\title{
Prospective study of sentinel headache in aneurysmal subarachnoid haemorrhage
}

\author{
Francisca H H Linn, Eelco F M Wijdicks, Yolanda van der Graaf, Francine A C Weerdesteyn-van Vliet, \\ Aad I M Bartelds, J van Gijn
}

\section{Summary}

Retrospective surveys of patients with subarachnoid haemorrhage suggest that minor episodes with sudden headache (warning leaks) may precede rupture of an aneurysm, and that early recognition and surgery might lead to improved outcome. We studied 148 patients with sudden and severe headache (possible sentinel headache) seen by 252 general practitioners in a 5-year period in the Netherlands.

Subarachnoid haemorrhage was the cause in 37 patients (25\%) (proven aneurysm in 21 , negative angiogram in 6 , no angiogram done in 6 , sudden headache followed by death in 4). 103 patients had headache as the only symptom, 12 of whom proved to have subarachnoid haemorrhage ( 6 with a ruptured aneurysm). Previous bouts of sudden headache had occurred in only 2 . Other serious neurological conditions were diagnosed in 18 . In the remaining 93 , no underlying cause of headache was found; follow-up over 1 year showed no subsequent subarachnoid haemorrhage or sudden death. In this cohort, acute, severe headache in general practice indicated a serious neurological disorder in $37 \%(95 \% \mathrm{Cl}$ $29-45 \%)$, and subarachnoid haemorrhage in $25 \%$ (18-32\%). $12 \%(5-18 \%)$ of those with headache as the only symptom.

The notion of warning leaks as a less serious variant of subarachnoid haemorrhage is not supported by this study. Early recognition of subarachnoid haemorrhage is important but will probably have only limited impact on the outcome in the general population.

Lancet 1994; 344: 590-93

\section{Introduction}

Acute severe headache is uncommon in general practice. The proportion of serious underlying disorders is unknown. ${ }^{1}$ In community-based series of aneurysmal subarachnoid haemorrhage (SAH) the mortality is about $50 \%$, despite the introduction of microsurgery and improvements in medical management. ${ }^{2}$ Many neurosurgeons and neurologists consider that early recognition of warning leaks, followed by emergency clipping of the aneurysm would be an advance in the treatment of subarachnoid haemorrhage. It is widely assumed that such minor bleeds precede a catastrophic event. Many patients with SAH recall a previous episode of headache that was unexpectedly severe, lasted several hours, and was sometimes accompanied by transient loss of consciousness, transient focal deficits, or neck stiffness. ${ }^{3-8}$ In a case-control study we found that approximately $40 \%$ of patients admitted with SAH reported previous episodes of severe headache, compared with only 1 of 20 patients admitted with cerebral infarction and none of 100 admitted with a non-neurological disorder. ${ }^{8}$ However, inquiries about these so-called warning leaks were made retrospectively and were hospital based..$^{3-8}$ It is not known whether a warning leak in SAH can be identified in general practice.

In the Netherlands virtually all medical disorders are first seen by general practitioners. We therefore initiated a prospective study of unusually severe acute headache in general practice.

\section{Patlents and methods}

From January, 1988, to January, 1993, 252 general practitioners were asked to report to the trial centre in Utrecht all patients with sudden severe headache and also to record all other patients with proven aneurysmal subarachnoid haemorrhage and cases of sudden death.

The study started with 60 general practitioners, allied to the Netherlands Institute of Primary Health Care, ${ }^{9}$ a network of general practitioners was covers $1 \%$ (about 150000) of the population and includes representatives in large cities and rural areas throughout the Netherlands. In 1990 and 1991 the number of general practitioners was increased to include general practitioners from the cities of Utrecht (approximately 230000 inhabitants) and Breda (approximately 125000). The size of a general practice averages about 2500 patients. For each year of the study the size of the population at risk was calculated, with adjustments for the number of participating practitioners and how long they had participated (table).

Patients were eligible if they attended the general practitioner's office or asked for a house call because of a sudden severe headache that started within one min or less and lasted for at least one hour. Vomiting, loss of consciousness, seizures, diplopia, weakness, and speech disorder were recorded, and patients were asked about previous similar headaches. The level of consciousness was graded according to the Glasgow Coma Scale from 3 to $14 .{ }^{10}$ Referal to a neurologist was left to the discretion of the practitioner. All patients were followed up for a year.

Once a year we collected information from participating practices about other patients with SAH about whom we had not been notified, usually because these patients had been seen by 


\begin{tabular}{|c|c|c|c|c|c|c|}
\hline & 1988 & 1989 & 1990 & 1991 & 1992 & Total \\
\hline $\begin{array}{l}\text { SAH } \\
\text { Reported } \\
\text { Not reported* }\end{array}$ & 3 & $\begin{array}{l}3 \\
4\end{array}$ & $\begin{array}{l}14 \\
11\end{array}$ & $\begin{array}{l}11 \\
10\end{array}$ & $\begin{array}{l}6 \\
12\end{array}$ & $\begin{array}{l}37 \\
38\end{array}$ \\
\hline Sudden death & 5 & 2 & 8 & 9 & 6 & $30 t$ \\
\hline $\begin{array}{l}\text { Estimated person- } \\
\text { years, } \times 100\end{array}$ & $\overline{1500}$ & $\overline{1500}$ & 3651 & 5687 & 5687 & 18025 \\
\hline $\begin{array}{l}\text { Incidence of SAH } \\
\text { per } 100000\end{array}$ & 20 & $\overline{47}$ & 68 & 3.7 & 32 & $\overline{42}$ \\
\hline
\end{tabular}

*Presentation other than with headache, seen by locum practitioner, or for other reasons not reported to the study office, including 1 patient found after completion of the study.

t1 had SAH on necropsy.

Table: Incidence of SAH and sudden death in the reglstration period of the study

associates or because they had presented with features other than headache. For patients with sudden death, relatives were asked about preceding episodes of sudden headache. To validate the completeness of our case ascertainment we went through the admission files of the emergency department of the University Hospital of Utrecht after completion of the study and checked if any patients with $\mathrm{SAH}$ registered with the participating practitioners in Utrecht had not been reported during the study period. This check identified only 1 such patient.

Patients seen by a neurologist were investigated by computed tomography (CT) or lumbar puncture. The diagnosis of SAH was based on the presence of extravasated blood in the basal cisterns on CT scanning, xanthochromia in cerebrospinal fluid (CSF), or evidence from necropsy. ${ }^{11}$ Patients with acute severe headache followed by death within hours were classified as probable SAH.

CT scans were reviewed by FHHL and EFMW and subarachnoid blood was measured: ${ }^{12} 10$ cisterns and fissures were graded as 0 (no blood), 1 (sedimentation), 2 (not completely filled), 3 (completely filled). Totals were grouped as large amounts (20-30), moderate amounts (10-20), and small or localised amounts of blood (1-10). CT scans with non-aneurysmal perimesencephalic haemorrhage were distinguished according to the pattern of bleeding and were similarly graded. ${ }^{13}$

Outcome of patients with SAH was determined 3 months after admission, according to the 5-point Glasgow Outcome Scale. ${ }^{14} \mathrm{We}$ divided this scale into death, vegetative state, or severe disability (poor outcome), and good recovery or mild disability that did not interfere with daily life (good outcome). CI $95 \%$ for incidence rates were calculated by Poisson methods.

\section{Results}

148 patients with acute and severe headache met the criteria for inclusion (figure), 4 died before investigations could be done; they were classified as probable SAH. 128 of the 144 surviving patients were referred to hospital; the remaining patients were not referred because they refused (3) or because the general practitioner considered another cause more plausible than SAH (13). In 18 of the referred patients no investigations were done because the neurologist considered the diagnosis of SAH unlikely.

Of 110 patients who were investigated, 33 had SAH. In 59 , no haemorrhage or other cause was found. Of the remaining 18 patients, 4 had an infectious disorder (herpes encephalitis confirmed at necropsy 1 , viral meningoencephalitis 1 , and viral meningitis 2), 9 had intracerebral haematomas (temporal lobe 6, occipital lobe 1 , and cerebellum 2, none consistent with aneurysmal haemorrhage-in 2 an arteriovenous malformation was the cause, as shown by angiography and operation); and 1 each had arteriovenous malformation with intraventricular bleeding, subdural haematoma, giant aneurysm with progressive neurological deficits but without haemorrhage, haemorrhage in a malignant glioma, and infarct from middle cerebral artery branch occlusion.
103 of the 148 patients $(70 \%)$ had headache without any other symptom, 12 of whom had SAH and 4 had another central nervous system disorder. In 33 patients, no investigations were done and in 54 the cause of the headache could not be identified.

Only 2 of the 37 patients with SAH had previously had a similar episode of headache: 1 had a sudden severe headache a month before admission and did not visit or call a general practitioner, and the other had an unusually severe headache 3 days before admission which subsided with medication from a general practitioner. In the 33 patients with SAH who reached hospital alive, the Glasgow Coma Scale was 14 in $18,11-13$ in 8 , and 7 or less in 7 . Neck stiffness on admission was found in 17. 2 had subhyaloid haemorrhages, and 7 had focal signs: hemiparesis (4), hemiparesis and oculomotor palsy (1), isolated sixth-nerve palsy (1), and isolated third-nerve palsy (1).

CT scanning was done in 31 of the 33 survivors with SAH who were investigated. In 25 , the films were available for review. Scans showed blood in the basal cisterns in 22 , of whom 10 also had intraventricular haemorrhage. The cisternal blood scores were $20-30$ in $10,10-20$ in 5 , and $1-10$ in 7.3 of these 22 had a non-aneurysmal, perimesencephalic pattern of haemorrhage. 1 other patient had blood in the subarachnoid space at the convexity. 2 had normal CT scans (after 5 and 21 days). In 1 of these, lumbar puncture revealed xanthochromic CSF (after 5 days) and the other had blood-stained CSF at the day of event.

Angiograms showed an aneurysm in 21 patients (anterior cerebral artery 8 , middle cerebral artery 6 , carotid artery 6 , and posterior inferior cerebellar artery 1 ) and were normal in 6 , including 3 with a perimesencephalic (nonaneurysmal) pattern of haemorrhage on CT. In the remaining 6 patients admitted to hospital with $\mathrm{SAH}$, angiography was not done, because of advanced age or poor clinical condition. In the 12 patients with SAH in whom

Number of patients with headache as the only symptom

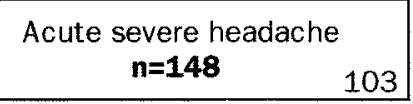

Cause

\begin{tabular}{|c|c|c|c|c|}
\hline $\begin{array}{l}\text { Not } \\
\text { investigated }\end{array}$ & $\begin{array}{l}\text { Negative } \\
\text { investigations }\end{array}$ & $\begin{array}{l}\text { Other } \\
\mathbf{n = 1 8}\end{array}$ & & $\begin{array}{l}S A H \\
n=33+4^{*}\end{array}$ \\
\hline$n=34$ & $n=59$ & & 4 & 12 \\
\hline
\end{tabular}

Angiography

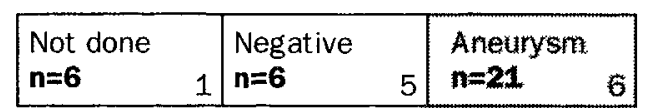

Surgery

\begin{tabular}{|l|l|}
\hline $\begin{array}{l}\text { Ineligible } \\
\mathbf{n}=\mathbf{3}\end{array}$ & $\begin{array}{l}\text { Operated } \\
\mathbf{n = 1 8}\end{array} \quad 6$ \\
\hline
\end{tabular}

Outcome

\begin{tabular}{|l|l|l|}
\hline $\begin{array}{l}\text { Poor } \\
n=2\end{array}$ & 1 & $\begin{array}{l}\text { Good } \\
n=16\end{array}$ \\
\hline
\end{tabular}

Figure: Summary of dlagnosis and outcome in 148 patlents with acute and severe headache in general practice, 1988-93

Inset: number of patients with headache as the only symptom. The group of 37 patients with SAH includes 4 patients who died before any investigation could be done. 
headache was the only symptom, angiography showed an aneurysm in 6 , was negative in 5 patients, and not done in 1 . 18 of the 21 patients with an aneurysm had an operation.

All 93 patients with acute headache but without a diagnosis of SAH or other neurological condition, whether or not referred to a neurologist, were followed up for a year after presentation. None of them subsequently had SAH, stroke, or sudden death. Recurrent headaches were reported by 11 patients.

38 additional patients with SAH were detected by inquiries during the 5 years of the study. They had not been entered because they had been seen by associates at night or during holidays (9), had presented with coma (8), or were deemed to have atypical features (10: confusion [2], associated trauma [3], fainting [2], or non-specific illness without headache having been a prominent symptom [3]), or because the general practitioner forgot about the study (11); none of them had had previous headaches. All additional patients were investigated with CT scanning, lumbar puncture, and/or angiography, except 2 who died at home within hours of onset. The aneurysm was clipped in 16 patients. There was a good outcome in 42 of all 75 patients with $\mathrm{SAH}(56 \%)(23 / 37[62 \%]$ in the study and $19 / 38[50 \%]$ outside).

There were 30 sudden deaths during the study without headache being a notable feature. In 14 of these, heart disease was suspected. None of these patients had been seen earlier with sudden and severe headache. Necropsy was done in $4 ; 1$ had an unsuspected SAH, and 3 had heart disease. On the basis of the 76 identified cases of SAH (37 within and 39 outside the study, including the patient who had died suddenly and had SAH proven by necropsy), the annual incidence of SAH during the 5-year study was $4 \cdot 2 / 100000 ;(95 \%$ CI 3.2-5.2). We compared our incidence rates with those derived from reported death rates at the Dutch Office of Statistics (ICD code 430). ${ }^{15}$ On the assumption of a mortality of $50 \%$, the incidence rate would be $5 \cdot 2$ per 100000 for men and $6 \cdot 8$ for women.

\section{Discussion}

Early recognition and surgical treatment of SAH may improve outcome. On the other hand, the low incidence of SAH and the high frequency of headache in general practice might result in patients being referred for investigation unnecessarily. The present study shows that general practitioners can identify unusually severe acute headaches that are associated with a high likelihood of a serious neurological disorder. During a 5-year period covering 1.8 million patient-years, only 148 patients were judged to have an unusually severe and acute headache. Serious neurological disorders were found in $37 \%$, including SAH in $25 \%$ and $\mathrm{SAH}$ due to aneurysmal rupture in $14 \%$. Patients with acute headache as the only symptom still had a $16 \%$ chance of life-threatening neurological disease, including a $12 \%$ chance of SAH and a $6 \%$ chance of SAH from aneurysmal rupture. SAH underlies about 1 in 4 of headaches with an acute onset, and patients with sudden severe headache lasting 1 hour or more, even if there are no other symptoms, need investigation.

We found an average annual incidence of 4.2 per 100000 . It is unlikely that patients with $\mathrm{SAH}$ were missed: all general practitioners participating in the study were asked every year about additional patients with SAH not reported to the trial centre, and a search through the files of the emergency department of the University Hospital Utrecht after the completion of the study revealed only 1 patient with SAH who was not reported by general practitioners. Our incidence rates (per 100000 ) are similar to those derived from the Dutch Office of Statistics ( $5 \cdot 2$ for men and 6.8 for women). Previous studies reported lower incidence rates (France $2 \cdot 2,95 \%$ CI 1.2-3.5); ${ }^{16}$ similar rates (Netherlands 8, 5.0-11.5, ${ }^{17}$ England 7.9, 5.4-10.8 ${ }^{10}$ ); and higher rates (Italy $10 \cdot 2,5 \cdot 6-16 \cdot 1 ;^{19}$ Finland $16 \cdot 8 ;^{20}$ New Zealand $14 \cdot 3 ;^{21}$ and USA 11$) .{ }^{22}$ Differences may be explained by study design, the populations studied (hospital or community), or by differences between countries.

Many earlier studies have speculated that minor leaks precede SAH. Our study suggests that these warning leaks are infrequent and that most first haemorrhages are serious. Our finding that only 2 of the 37 reported patients with SAH had had previous episodes of headache is probably inherent in the study design, but no such history was found in any of the 37 patients with SAH identified later, nor in the 30 patients who died suddenly. Furthermore, in the 93 patients who did not have SAH or other serious central nervous system disorders, no SAH or other neurological disorder occurred during a follow-up of 1 year. This confirms our earlier finding that in patients with nonhaemorrhagic sudden severe headache, haemorrhages do not occur later. ${ }^{23,24} \mathrm{~A}$ large proportion of patients in that study later developed migraine, suggesting that unusually severe sudden headache can be a presenting symptom. ${ }^{23}$

The notion of small aneurysmal leaks presupposes subtle clinical signs and small amounts of cisternal blood on CT scanning, or negative CT-scan findings with only CSF xanthochromia; yet half the patients with proven SAH had impaired consciousness, and only 2 had xanthochromic or blood-stained CSF and negative CT scan, which in both cases could be explained by a long interval before CT scan ( 5 days and 3 weeks), with clearance of extravasated blood from the subarachnoid cisterns. The 22 patients with evidence of SAH on CT scan had a similar amount of extravasated blood to that previously reported in a large hospital series of patients with SAH. ${ }^{25}$ Previous studies reported warning signs in 15-60\% of patients with SAH..$^{3-7}$ Patients in those studies were questioned in hospital during a serious illness, and minor headaches in the recent past could easily have been overinterpreted as minor bleeds. This recall bias may also have operated in our previous case-control series, in which patients with cerebral infarction served as a control group. ${ }^{8}$

An alternative notion of minor bleeding is that it remains restricted to the wall of an aneurysm with subsequent expansion. There has been one case report of a patient with a previous episode of headache in whom necropsy showed an organised thrombus with phagocytes adjacent to the ruptured aneurysm. ${ }^{26}$ Our negative findings and a previous follow-up study of patients with sudden headache and no evidence for $\mathrm{SAH}^{23}$ suggest that this form of warning headache is unusual. It has also been suggested that warning signs and symptoms are caused by enlarging aneurysms, without rupture. Those cases are often associated with painful cranial nerve palsy, ${ }^{27,28}$ a feature not encountered in this study. During our study the general practitioners reported 2 patients who presented with sudden oculomotor palsy associated with an enlarging posterior communicating aneurysm. In neither patient, however, had there been episodes of headache.

A good outcome at 1 year was found in 16 of 21 patients with aneurysms, a proportion similar to that in surgical series. ${ }^{29}$ The outcome in all initially surviving patients with 
SAH including those outside our headache-surveillance study was good in 42 of $75(56 \%)$, a proportion not substantially different from hospital-based reports. ${ }^{2,19,21,29}$ Nor did the clinical and radiological characteristics of the patients with SAH differ substantially from findings in previous hospital series. Even in this large study with highly motivated general practitioners we did not find minor, premonitory haemorrhages. This suggests that increased awareness of general practitioners may result in only a small improvement in overall outcome of SAH.

We thank the general practitioners, consultant neurologists, and the Nederlands institut voor onderzoeh von de eerstelynsqezond-heidszorg (NIVEL) for participating in the study; Dr G J E Rinkel and Dr A Algra for helpful comments; and Mrs J P van Andel for help with data management.

Supported by the Dutch Heart Foundation (grant number 89.097), grant to EFMW).

\section{References}

1 Rasmussen BK, Olesen J. Symptomatic and nonsymptomtic headaches in a general population. Neurology 1992; 42: 1225-31.

2 Hijdra A, Braakman R, van Gijn J, Vermeulen $M$, van Crevel $H$. Aneurysmal subarachnoid hemorrhage. Complications and outcome in a hospital population. Stroke 1987; 18: 1061-67.

3 Okawara $\mathrm{SH}$. Warning signs prior to rupture of an intracranial aneurysm. $\mathcal{J}$ Neurosurg 1973; 38: 575-80.

4 Duffy GP. The "warning leak" in spontaneous subarachnoid haemorrhage. Med F Aust 1983; 1: 514-16.

5 Leblanc R, Winfield JA. The warning leak in subarachnoid hemorrhage and the importance of its early diagnosis. Can Med Assoc $\mathcal{F}$ 1984; 131: 1235-36.

6 Hauerberg J, Andersen BB, Eskesen V, Rosenørn J, Schmidt K. Importance of the recognition of a warning leak as a sign of a ruptured intracranial aneurysm. Acta Neurol Scand 1991; 83: 61-64.

7 Juvela S. Minor leak before rupture of an intracranial aneurysm and subarachnoid hemorrhage of unknown etiology. Neurosurg 1992; 30: $7-11$.

8 Verweij RD, Wijdicks EFM, van Gijn J. Warning headache in aneurysmal subrachnoid hemorrhage. Arch Neurol 1988; 45: 1019-20.

9 Collette HJA. The sentinel practices system in the Netherlands. In: Leaverton PE, Massé L, Simches SO, eds. Enviromental epidemiology. New York: Praeger, 1982: 149-57.

10 Teasdale GM, Jennet B. Assessment of coma and impaired consciousness: a practical scale. Lancet 1974; ii: 81-84.

11 Vermeulen $M$, van Gijn J. The diagnosis of subarachnoid haemorrhage. I Neurol Neurosurg Psychiatry 1990; 53: 365-72.

12 Hijdra A, Brouwers PJAM, Vermeulen M, van Gijn J. Grading the amount of blood on computed tomograms after subarachnoid hemorrhage. Stroke 1990; 21: 1156-61.

13 Rinkel GJE, Wijdicks EFM, Vermeulen M, et al. Nonaneurysmal perimesencephalic subarachnoid hemorrhage: CT and $M R$ pattern that differ from aneursymal rupture. $A \mathcal{F} N R$ 1991; 12: 829-34.

14 Jennett $B$, Bond $M$. Assessment of outcome after severe brain damage: a practical scale. Lancet 1975 ; i: $480-84$.

15 Centra Bureau voor de Statistiek Nederland. Primaire doodsoorzaken, absolute aantallen. 's-Gravenhage: CBS annual publication; serie A1, 1989.

16 Giroud $M$, Milan C, Beuriat $P$, et al. Incidence and survival rates during a two-year period of intracerebral and subarachnoid haemorrhages, cortical infarcts, lacunes and transient ischaemic attacks. The stroke registry of Dijon: 1985-1989. Int $\mathcal{F}$ Epidemiol 1991; 20: 892-99.

17 Herman B, Leyten ACM, Luijk van JH, Frenken CWGM, Op de Coul AAW, Schulte BPM. Epidemiology of stroke in Tilburg, the Netherlands. The population-based stroke incidence register: 2 . incidence, initial clinical picture and medical care, and three-week case fatality. Stroke 1982; 13: 629-34.

18 Bamford J, Sandercock P, Dennis M, Burn J, Warlow C. A prospective study of acute cerebrovascular disease in the community: the Oxfordshire Community Stroke Project-1981-86. 2. Incidence, case fatality rates and overall outcome at one year of cerebral infarction, primary intracerebral and subarachnoid haemorrhage. $\mathcal{F}$ Neurol Neurosurg Psychiatry 1990; 53: 16-22.

19 Ricci S, Celani MG, La Rosa F, et al. SEPIVAC: a community-based study of stroke incidence in Umbria, Italy. $\mathcal{F}$ Neurol Neurosurg Psychiatry 1991; 54: 695-98.

20 Pakarinen $S$. Incidence, aetiology, and prognosis of primary subarachnoid haemorrhage: a study based on 589 cases diagnosed in a defined urban population during a defined period. Acta Neurol Scand 1967; 43 (suppl 29): 1-128.

21 Bonita R, Thomson S. Subarachnoid hemorrhage: epidemiology, diagnosis, management and outcome. Stroke 1985; 16: 591-94.

22 Ingall TJ, Whisnant JP, Wiebers DO, O'Fallon WM. Has there been a decline in subarachnoid hemorrhage mortality? Stroke $1989 ; 20$ : 718-24.

23 Wijdicks EFM, Kerkhoff H, van Gijn J. Long-term follow-up of 71 patients with thunderclap headache mimicking subarachnoid haemorrhage. Lancet 1988; ii: 68-70.

24 Markus HS. A prospective follow-up of thunderclap headache mimicking subarachnoid haemorrhage. $f$ Neurol Neurosurg Psychiatry 1991; 54: 1117-18.

25 Brouwers PJAM, Dippel DWJ, Vermeulen $M$, Lindsay $K W$, Hasan D, van Gijn J. Amount of blood on computed tomography as an independent predictor after aneurysm rupture. Stroke 1993; 24: 809-14.

26 Ball MJ. Pathogenesis of the "sentinel headache" preceding berry aneurysmal rupture. CMA fournal 1975; 112: 78-79.

27 Raja IA. Aneurysm induced third nerve palsy. $\mathcal{F}$ Neurosurg 1972; 36: 548-51.

28 Kissel JT, Burde RM, Klingele TG, Zeiger HE. Pupil-sparing oculomotor palsies with internal carotid-posterior communicating artery aneurysms. Ann Neurol 1983; 13: 149-54.

29 Kassell NF, Torner JC, Haley EC, Jane JA, Adams HP, Kongable GL. The international cooperative study on the timing of aneurysm surgery. Part 1: overall management results. $\mathcal{F}$ Neurosurg 1990; 73: $18-36$ 